\title{
Erratum to: Investigation of the first-order metamagnetic transitions and the colossal magnetocaloric effect using a Landau expansion applied to MnAs compound
}

\author{
A.M.G. Carvalho ${ }^{1, a}$, A.A. Coelho ${ }^{2}$, S. Gama ${ }^{2}$, F.C.G. Gandra ${ }^{2}$, P.J. von Ranke ${ }^{3}$, and N.A. de Oliveira ${ }^{3}$ \\ 1 Divisão de Metrologia de Materiais (DIMAT), Instituto Nacional de Metrologia, Normalização e Qualidade Industrial (IN- \\ METRO), Duque de Caxias, RJ, 25250-020, Brasil \\ 2 Instituto de Física "Gleb Wataghin", Universidade Estadual de Campinas, Unicamp, 13083-970, Campinas, São Paulo, Brasil \\ 3 Instituto de Física, Universidade do Estado do Rio de Janeiro (UERJ), 20550-013, Rio de Janeiro - RJ, Brasil
}

Eur. Phys. J. B 68, 67 (2009)

Received 17 May 2010

Published online 20 October 2010 - (c) EDP Sciences, Società Italiana di Fisica, Springer-Verlag 2010

Revising the original paper [1], we have notice a wrong transformation of units, which caused wrong values of the experimental magnetization. To fit the corrected experimental values, we use new theoretical parameters. A few values along the text were changed. In spite of the corrections, the conclusions were not changed.

The new theoretical parameters (second paragraph of Results and discussion section) are: $\alpha=$ $0.2520 \mathrm{~T}^{2} \mathrm{~K}^{-1} \mathrm{meV}^{-1}, \beta=0.7171 \mathrm{~T}^{4} \mathrm{meV}^{-3}$ and $\gamma=$ $0.0622 \mathrm{~T}^{6} \mathrm{meV}^{-5}$. $\Phi_{0}(T)$ was chosen to give a maximum magnetic entropy $S^{\max }=R \ln (2 J+1)=$ 13.4 $\mathrm{J} \mathrm{mol}^{-1} \mathrm{~K}^{-1}$, which corresponds to the total angular moment $J=2$.

In the eighth paragraph, the new values of theoretical entropy variations at $0 \mathrm{kOe}$ are 5.7 and $10.8 \mathrm{~J} \mathrm{~mol}^{-1} \mathrm{~K}^{-1}$ on heating and on cooling, respectively. At $50 \mathrm{kOe}$, the new values are 4.3 and $5.3 \mathrm{~J} \mathrm{~mol}^{-1} \mathrm{~K}^{-1}$ on heating and on cooling, respectively. These values are larger than those reported in references $[1,2]$.

In the ninth paragraph, the new values of theoretical $\Delta S_{T}$ maxima are 8.6 and $11.6 \mathrm{~J} \mathrm{~mol}^{-1} \mathrm{~K}^{-1}$ on heating and on cooling, respectively. The first value is larger than those in references $[1,3,4]$.

Figures 1 to 5 should undergo changes, but these are only quantitative, keeping the same profile, and do not change any conclusion of the paper. The correction in the experimental magnetization is obtained multiplying the old values by the factor of 1.688. The new theoretical curves can be easily obtained using the new parameters cited above.
An extra correction, which is not related to the new parameters, must be performed in the third paragraph of the same section. In the passage "the curve $H_{1}(T)$ separates the ferromagnetic phase (FM) from the region of metastability during the heating process of the system. Meanwhile, the curve $H_{2}(T)$ separates that region of metastability from the paramagnetic phase (PM), during the cooling process", we must exchange "heating process" by "cooling process" and vice-versa. In the passage "the curve $H_{1}(T)$ separates the ferromagnetic phase from the region of metastability when the process is performed decreasing the magnetic field. The curve $H_{2}(T)$ separates the paramagnetic phase from the region of metastability when increasing the magnetic field", we must exchange "decreasing the magnetic field" by "increasing the magnetic field" and vice-versa.

\section{References}

1. A.M.G. Carvalho, A.A. Coelho, S. Gama, F.C.G. Gandra, P.J. von Ranke, N.A. de Oliveira, Eur. Phys. J. B 68, 67 (2009)

2. L. Tocado, E. Palacios, R. Burriel, J. Therm. Anal. Calorim. 84, 213 (2006)

3. H. Wada, K. Tanigushi, Y. Tanabe, Mater. Trans. 43, 73 (2002)

4. S. Gama, A.A. Coelho, A. de Campos, A.M.G. Carvalho, F.C.G. Gandra, P.J. von Ranke, N.A. de Oliveira, Phys. Rev. Lett. 93, 237202 (2004)

\footnotetext{
${ }^{a}$ e-mail: amcarvalho@inmetro.gov.br
} 